\title{
Jakob von Uexküll y el problema de los mundos (circundantes) humanos*
}

\section{Jakob von Uexküll and the problem of human (surroundings) worlds}

\author{
JUAN MANUEL HEREDIA \\ Universidad de Buenos Aires/ Centro de Historia Intelectual (UNQ)
}

Recibido: 14/04/2020 Aceptado:29/11/2020

\section{RESUMEN}

El artículo analiza el problema de los mundos humanos a partir del concepto de mundo circundante (Umwelt) que J. von Uexküll plantea para pensar la existencia animal. En este sentido, (1) introduce dicho concepto biológico y sus implicancias, (2) reconstruye las interpretaciones y críticas que se le formulan en la antropología filosófica alemana de principios del siglo XX, y (3) defiende la idea según la cual, desde un horizonte arqueológico, habría una oposición correlativa entre el Umwelt biológico y las ideas filosóficas de mundo humano previamente tematizadas.

\section{PALABRAS CLAVE \\ JACOB VON UEXKÜLL, MUNDO CIRCUNDANTE; MUNDO, ANTROPOLOGÍA FILOSÓFICA ALEMANA, SUBJETIVIDAD}

\begin{abstract}
The article analyzes the problem of human worlds in the light of the concept of surrounding world (Umwelt) that J. von Uexküll proposes to think animal existence. In this sense, (1) introduces said biological concept and its implications, (2) reconstructs the interpretations and criticisms addressed to him in early 20th century German philosophical anthropology, and
\end{abstract}

*Este artículo fue escrito en el marco de una Beca Posdoctoral del Consejo Nacional de Investigaciones Científicas y Técnicas (CONICET) de Argentina.

(C) Contrastes. Revista Internacional de Filosofía, vol. XXVI ${ }^{\circ} \mathrm{N}^{\circ} 1$ (2021), pp. 43-63. ISSN: 1136-4076

Departamento de Filosofía, Universidad de Málaga, Facultad de Filosofía y Letras Campus de Teatinos, E-29071 Málaga (España) 
(3) defends the idea according to which, from an archaeological horizon, there would be a correlative opposition between the biological Umwelt and the philosophical ideas of the human world previously thematized.

\author{
KEYWORDS \\ JACOB VON UEXKÜLL, SURROUNDING WORLD, WORLD, GERMAN \\ PHILOSOPHICAL ANTHROPOLOGY, SUBJECTIVITY
}

\title{
I. INTRODUCCIÓN
}

«SóLO QUIENES NO SABEN leer se asombrarán de que lo haya apresado más claramente en Cuvier, en Bopp y en Ricardo que en Kant o en Hegel» (Foucault 2002, p. 299). Con esta frase el filósofo francés indicaba, en Las palabras y las cosas (1966), que el sistema de pensamiento de una época (esto es, las condiciones de visibilidad de los objetos y el conjunto de reglas que rigen la producción de enunciados), se manifiesta y efectúa en un conjunto diverso de prácticas discursivas, y no necesariamente en las obras canónicas de la filosofía del período (las cuales, por otra parte, participan de dicho sistema tanto como otro tipo de regiones epistémicas). ${ }^{1}$ Uno de los elementos que Foucault destaca para pensar la coherencia de un sistema de pensamiento es la noción de «oposición intrínseca», que tematiza la coexistencia de conceptualizaciones antagónicas cuya mutua exclusión revela su arraigo en un código común, en una misma episteme. ${ }^{2}$ En este sentido, por ejemplo, David Ricardo y Marx, la economía burguesa y la economía revolucionaria, ofrecen dos respuestas opuestas pero en función de una problemática común, que es producto de una determinada disposición epistemológica. ${ }^{3}$

La tesis que defiende este artículo es que la biología teórica de Jakob von Uexküll (1864-1944) constituye un índice fructífero para tematizar el sistema de pensamiento que se despliega en la primera parte del siglo XX. $\mathrm{Y}$, más concretamente, que para la antropología filosófica alemana que le es coetánea y lo discute, la teoría de Uexküll es mucho más que una referencia

1 En este sentido, el proyecto teórico-metodológico arqueológico promovido por Foucault propone situarse en un segundo orden de análisis y tematizar, no el contenido de los discursos (dimensión semántica) o la intención de los autores al producirlos (dimensión pragmática), sino la dimensión sintáctica y estructural que les subyace y los hace posibles. De este modo, los discursos de una época presuponen y expresan un determinado lenguaje, un orden del saber o una episteme, que delimita un orden de lo visible y lo decible, ciertos criterios de cientificidad, determinadas reglas para la producción de enunciados, etc.

2 Cf. Foucault 2011, pp. 198-202.

3 Cf. Foucault 2002, pp. 256-257. 
biológica. El objetivo de este trabajo es reconstruir dicho campo problemático y mostrar que, desde un punto de vista arqueológico, el concepto uexkülliano de mundo circundante (Umwelt) funciona como «oposición intrínseca» frente a las proposiciones filosóficas que ven en el mundo el ámbito privilegiado para tematizar el carácter espiritual que definiría al ser humano. Antes de dar lugar a este análisis caben algunas precisiones teórico-metodológicas. En principio, si uno se atiene a la periodización de la arqueología foucaultiana, podría surgir el interrogante respecto de en qué sistema de pensamiento emplazar a Uexküll. En efecto, como es sabido, el filósofo francés plantea que la episteme moderna (o «Edad de la Historia») designa un orden del saber que domina todo el siglo XIX y que se quebraría a mediados del siglo XX con el desarrollo del estructuralismo. Retomando esta línea arqueológica, uno de los principales estudiosos de la obra de Uexküll, Kalevi Kull (2004), plantea que su teoría biológica sería expresión de un «evolucionismo posmoderno» que, a diferencia del evolucionismo moderno y decimonónico, no estaría centrado en la filogénesis sino en un análisis del fenómeno biológico en términos de funcionamientos sistémicos, redes ecológicas y relaciones biosemióticas. ${ }^{4}$

Por nuestra parte, creemos que es posible otra perspectiva. En este punto, hacemos nuestra la revisión de la arqueología foucaultiana emprendida por Elías José Palti (2003, 2017), quien, en el marco de una renovación teóricometodológica de la historia intelectual, plantea que allí donde Focuault ve una episteme (la moderna) hay, de hecho, dos: un orden del saber propio del siglo XIX (Era de la Historia), y un sistema de pensamiento que comienza a perfilarse en 1890, se instaura a principios del siglo XX y se extiende hasta la década de 1970. Palti llama a esta configuración histórico-epistemológica Era de las formas y señala tres rasgos fundamentales. En primer lugar, la neutralización de las perspectivas teleológicas y/o historicistas-evolucionistas del diecinueve, y la promoción de enfoques sincrónicos, estructurales y formales. Ese movimiento se registra en la electrodinámica y la física de campos (que desplaza a la física de los elementos sustanciales), la psicología de la forma (que desmonta las premisas atomistas de la psicofísica y la psicofisiología), la lingüística de Saussure (que instala una visión estructural de la lengua y mina desde sus cimientos a la filología comparada), los estudios de regulación y regeneración en biología, el neovitalismo y el mutacionismo (que se enmarcan en el período de «eclipse del darwinismo»

4 En este sentido, Kull (2004, p. 101) afirma: «lo que sucede con el evolucionismo al pasar de lo moderno a lo posmoderno, es que dejamos atrás todo el concepto de progreso de la vida tal como se expresa en el árbol de la vida y en su lugar entendemos la evolución como modificaciones en la red de la vida». 
acaecido entre 1890 y 1930). ${ }^{5}$ En segundo lugar, la emergencia del fenómeno de la discontinuidad en física y en biología. En este punto, las ideas de salto cuántico, mutación y cambio brusco operaron como elementos decisivos para destituir las premisas historicistas-evolucionistas decimonónicas, y efectuar una disociación de la noción de totalidad con respecto a la de finalidad. Dichos fenómenos, corroborables antes de ser explicables, plantearon frontalmente el problema de cómo concebir racionalmente el paso de una forma a otra, pues supusieron una ruptura con respecto a las secuencias causales y las fases ordenadas teleológicamente (que, en el siglo XIX, explicaban la articulación entre orden y cambio sobre la base de una temporalidad histórica). Surge así una situación paradójica en la cual cabe pensar la génesis de los sistemas a partir de mutaciones súbitas y discontinuas de carácter contingente, saltos que pueden ser establecidos y puestos de manifiesto, pero que resultan inexplicables en términos causales, evolutivos o teleológicos. En tercer lugar, y en relación con dicha problemática, se produce en filosofía un retorno de la metafísica. Y, frente a los puntos ciegos de las explicaciones científicas y ante el agotamiento del positivismo, se cristaliza en el pensamiento occidental una oposición correlativa entre formas y vida, entre sistemas autorregulados y acción intencional, entre estructuralismo y fenomenología. Dicha oposición implica que a las formas y a las estructuras la génesis y el cambio les viene, necesariamente, desde afuera (vida, sujeto, existente, etc.).

Consideramos que, en la Era de las formas, Uexküll se encuentra en su lugar: su anti-darwinismo y su rechazo de los enfoques filogenéticos, su promoción de una biología estructural contra el mecanicismo fisicoquímico, sus cercanías y distancias con respecto al neovitalismo, su afirmación de la existencia de sistemas sujeto-mundo, su propuesta de investigar el comportamiento animal en función de su observación en el espacio y no de especulaciones genealógicas, su tematización de la subjetividad animal desde un horizonte trascendental, su aporte de un concepto de causalidad retroactiva proto-cibernético... todos estos elementos presuponen y expresan las condiciones histórico-epistemológicas reseñadas.

Creemos que Kull conceptualiza a Uexküll como un biólogo «posmoderno» no sólo por su adopción de la periodización foucaultiana, también porque se basa en su último libro (Teoría de la significación) y, sobre todo, en la interpretación que de dicho libro hizo la corriente biosemiótica (de la que forma parte) desde fines de 1970. Basamos esta percepción en dos razones. Una concierne al desarrollo de la obra uexkülliana, otra a su relación con la filosofía del siglo XX. Respecto de esto último, y desde un punto de vista histórico-intelectual, vislumbramos tres grandes líneas de análisis e

5 Respecto del concepto de «eclipse del darwinismo», véase: Huxley 1948, pp. 22-28. 
interpretación. Por un lado, frente al mecanicismo, Uexküll afirma que la vida es un factor inmaterial, pero, contra los vitalistas (Driesch, Bergson, Simmel), sostiene que dicho factor no es una fuerza, impulso o tendencia de orden psicológico sino la efectuación de una estructura. En este sentido, frente a la antinomia entre las formas y la vida que se consolida en las primeras décadas del siglo XX, Uexküll (1944, p. 50) afirma la ecuación «Vida igual a Forma». ${ }^{6}$ Por otro lado, entre 1927 y 1944, encontramos una masiva invocación de sus conceptos en el debate filosófico-antropológico alemán, donde sus tesis sobre los mundos circundantes son discutidas por Scheler, Heidegger, Plessner, Goldstein, Gehlen y Cassirer. Esta línea será la que acaparará la atención de este artículo, y a ella se debería añadir la gran influencia que Uexküll ejerce en Ortega y Gasset ${ }^{7}$, así como la lectura de Lacan y el primer libro de Merleau-Ponty, que también refieren a la cuestión antropológica. Por último, encontramos un conjunto de interpretaciones que abordan la obra uexkülliana desde un horizonte ontológico, post-antropológico y/o semiótico, y que, según nuestro análisis, arraigan en un orden del saber distinto al del propio Uexküll. En esta línea ubicamos la relectura que opera Merleau-Ponty en sus cursos sobre la Naturaleza (1956-1960) y, fundamentalmente, los desarrollos de la biosemiótica desde fines de la década de 1970 y la década del ochenta ${ }^{8}$, así como la lectura que construye Deleuze (y Guattari) entre 1978 y 1991.

La obra de Uexküll, por otra parte, no es una construcción de una sola pieza, sino que va evolucionando en función de sucesivas rectificaciones e innovaciones conceptuales. Según nuestro análisis, es posible distinguir cuatro momentos: (1) el período de formación académica, donde cobran relevancia sus investigaciones fisiológicas y el concepto de plan de construcción (Bauplan) como objeto de la biología (1892-1905); (2) el momento de despliegue de su biología teórica a través de las nociones de conformidad a plan (Planmäßigkeit), mundo perceptible (Merkwelt) y mundo circundante (Umwelt) (1907-1920); (3) el período de reelaboración de su teoría de los mundos circundantes a partir de la introducción del concepto de círculo funcional (Funktionskreis) y, con él, la apertura a una dimensión no ya solo semántica sino también pragmática del comportamiento animal (1920-1936); (4) sus últimas reflexiones relativas a la idea de Naturaleza, y a la relación entre mundos circundantes heterogéneos, sobre la base de una teoría relacional de la significación (1938-1944). ${ }^{9}$

6 Hemos analizado esta cuestión en Heredia 2021.

7 Sobre esta cuestión, véanse las propias palabras de Ortega en Uexküll 1924, p. 297; 1951, p. 8.

8 Entre los principales referentes de esta corriente se cuentan Thomas Sebeok, Thure von Uexküll (hijo de Jacob von Uexküll), Jesper Hoffmeyer, Claus Emmeche, Kalevi Kull, Terrence Deacon, y John Deely.

9 Hemos expuesto y fundamentado esta periodización en Heredia 2020. 
Mientras las lecturas filosóficas de fines del siglo XX toman como referencia privilegiada este último momento de su pensamiento, el debate del que fue objeto en la antropología filosófica alemana encuentra su eje en el segundo y en el tercer momento, focalizándose en el concepto de mundo circundante. En el próximo apartado introduciremos este concepto y, en el subsiguiente, reconstruiremos el debate de la antropología filosófica alemana con Uexküll a propósito del problema de los mundos (circundantes) humanos.

\section{LA VIDA ES EL MUNDO}

En julio de 1916 un joven Ludwig Wittgenstein (2009, p. 100) escribe en su diario «El mundo y la vida son uno. La vida fisiológica no es, naturalmente, 'la vida'. Y tampoco la psicológica. La vida es el mundo». Años más tarde, agrega: «Los límites de mi lenguaje significan los límites de mi mundo» (1997, p. 143). Uexküll está lejos de la filosofía de Wittgenstein, pero cerca de estas proposiciones. Para él, la fisiología mecanicista ocluye una auténtica visión biológica y esconde con su analítica de tropismos y estímulos una totalidad que unifica al sujeto con el mundo. ${ }^{10}$ Por otro lado, deslinda su biología de toda tentativa de psicología animal, y pone entre paréntesis la cuestión de la afectividad en provecho de un análisis de la percepción y la acción. ${ }^{11}$ Finalmente, subraya que la vida animal está siempre ya en un mundo y no puede no estarlo. Las dos imágenes que Uexküll emplea para ilustrar esto último son sobrecogedoramente claustrofóbicas: desde el punto de vista espacial, el sujeto animal está encerrado en una burbuja ${ }^{12} \mathrm{y}$, desde el punto de vista temporal, avanza a tientas en un túnel. ${ }^{13}$ Lo dicho se deriva de su concepto de mundo circundante (Umwelt), definido en 1934 en los siguientes términos: «todo lo que un sujeto percibe se torna su mundo perceptual, y todo su obrar se vuelve su mundo efectual. Mundo perceptual y mundo efectual conforman juntos una unidad cerrada: el mundo circundante.» (Uexküll 2016, p. 35). El mundo perceptual o mundo perceptible, Merkwelt, se compone del conjunto limitado de «portadores de significación» que puede percibir un sujeto animal específico. ${ }^{14}$ No cualquier estímulo tiene significación para un animal sino solo aquellos que, en función de su estructura biológica y fisiológica, tienen relevancia y pueden ser divisados. El mundo efectual o mundo de acción, Wirkwelt, es producto de la suma de gestos, acciones y potencias efectoras que el animal acredita en su faz activa y que modifican

10 Cf. Uexküll 1926, pp. 330-331; 2016, p. 39.

11 Cf. Ibid., pp. 226-227, 328-329; 1951, pp. 60-79.

12 Cf. Uexküll 2016, p. 35.

13 Cf. Uexküll 1926, pp. 306-307.

14 Cf. Ibid., p. 126. 
a sus portadores de significación, y, como en el caso anterior, encuentra su condición en la estructura que el animal pone en funcionamiento. Uexküll llama a esta estructura Bauplan (plan de construcción, o tipo de estructura, de un ser viviente), aclara que la misma «no es una cosa material, sino, más bien, una unidad de la relación inmaterial que existe entre las diferentes partes de un cuerpo animal» (Uexküll 1944, p. 9), y plantea que tanto en percepción como en acción el animal está condicionado a priori por dicha estructura específica (la cual se manifiesta fisiológicamente en la posesión de determinados órganos receptores, centrales y efectores, y biológicamente en la posesión de esquemas, secuencias de impulsos y reglas que rigen inmaterialmente el funcionamiento del cuerpo material).

Entre el mundo perceptible y el mundo de acción Uexküll sitúa el concepto de círculo funcional (Funktionskreis). Este explica el modo a través del cual el sujeto construye su mundo circundante, respondiendo con acciones a la recepción de significaciones. «La vida exterior de todo animal», dice Uexküll (2014, p. 88), «se compone de un número mayor o menor de círculos funcionales. El resultado del funcionamiento es siempre una destrucción o transformación del portador de características». El mundo circundante de un sujeto, por tanto, se compone de un conjunto de círculos funcionales que articulan significaciones y operaciones. ${ }^{15}$ De aquí se desprende que «sin un sujeto viviente no puede haber ni espacio ni tiempo» (Uexküll 2016, p. 49) y, por otro lado, que los animales son «sujetos cuya actividad esencial consiste en percibir y obrar» (ibid., p. 35). Para Uexküll, el sistema sujeto-mundo circundante es la unidad mínima de la existencia biológica, y esto implica que el viviente no lucha contra el mundo ni se adapta a un medio hostil, sino que constituye perceptivamente y construye operativamente su propio mundo circundante «conforme a plan» (Planmäßigkeit). Cada animal es, así, el centro de una esfera hueca y el eje de un cilindro horizontal. Y ello conduce a acreditar la coexistencia de una multitud de mundos vivientes en el mismo espacio físico y, correlativamente, a replantear el problema del solipsismo: hay tantos mundos como sujetos.

Este escándalo de la pluralidad de subjetividades animales, y el desafío que lanza a la idea de subjetividad humana, no pasará desapercibido. De hecho, es posible ver en él el índice de dos procesos correlacionados: un marcado declive en la pretensión de encontrar en la idea de vida el punto focal

15 Dentro de ese conjunto, se destacan cuatro grandes círculos funcionales que organizan la existencia biológica: el del ambiente (que refiere, fundamentalmente, a las señales que recibe un animal al pasar de un medio acuático a un medio aéreo, por ejemplo, y que lo impelen a volver a su ambiente de existencia natural); el del alimento; el del enemigo; el de la sexualidad y la reproducción. $C f$. Ibid., pp. 127-129 
para pensar la libertad humana frente a los automatismos, y la emergencia del par cerrado/abierto para pensar la diferencia ontológica que separa al animal del ser humano. En este sentido, como apunta Blumenberg (2013, p. 23), el eclipse de las filosofías de la vida a manos de filosofías del ser encuentra un umbral temporal en la década que va desde la muerte de Simmel en 1918 a la publicación de Ser y tiempo en 1927. En este lapso, la asociación entre las ideas de vida y de mundo se va haciendo cada vez más estrecha, y creemos que Uexküll constituye un elemento clave para pensar este proceso. Dos casos nos permiten ilustrar el punto. A principios del siglo XX, Wilhelm Dilthey introduce el concepto de Weltanschauung (cosmovisión, visión del mundo) y señala que, por debajo de la relatividad de las cosmovisiones, más allá de la discontinuidad entre éstas, se encuentra la vida. En 1912 escribe: «la última raíz de la visión del mundo es la vida» (Dilthey 1974, p. 41), esto es, a la base de toda cosmovisión hay una disposición vital afectada por regularidades psíquicas. ${ }^{16}$ La vida inter-psíquica es determinante en las estructuras de mundo y se suman a ella otras condiciones que hacen a la diversidad de las distintas cosmovisiones. ${ }^{17}$ Así, en el plano histórico-social, la vida se opone al mundo como el fundamento a lo fundado. También Simmel acredita este carácter fundamental de la vida con relación al mundo y sus formas culturales. En 1918, y a la sombra de Uexküll, ${ }^{18}$ plantea que, frente a la rígida «teleología de los animales», «el hombre es el ser menos teleológico» que hay (Simmel 2004, p. 57). Su libertad, de hecho, reside en poder rebasar los límites que se hallan inscriptos en su estructura corporal y las funciones que esta organización prescribe. La creación de microscopios y telescopios, por ejemplo, muestra hasta qué punto los seres humanos han sobrepasado los marcos de su percepción natural, ${ }^{19}$ y lo mismo cabría decir de los aparatos que multiplican su potencia efectora. Simmel, sin embargo, no renuncia a una categoría metafísica de vida sino que, por el contrario, ve en ella la quintaesencia de un movimiento de autotrascendencia que definiría a la vida espiritual humana (e, incluso, a algunas zonas de la vida fisiológica, como ser la reproducción y la muerte). ${ }^{20}$ De allí que se encuentre en las antípodas de la ecuación uexkülliana vida $=$ forma. ${ }^{21}$ Esta ecuación, y la afirmación de la existencia biológica de sistemas sujeto-mundo circundante, contribuyen a devaluar las promesas metafísicas incluidas en la noción de vida y dan lugar

$16 C f$. Dilthey 1974, p. 44.

17 Entre estas condiciones Dilthey (ibid., p. 47) incluye: «El clima, las razas, las naciones determinadas por la historia y la formación de los Estados».

18 Cf. Simmel 2004, p. 28.

19 Cf. Ibid., pp. 28-29.

20 Cf. Ibid., pp. 40-43.

$21 C f$. Heredia 2021. 
a una conceptualización que, en lo sucesivo, fusionará vida y mundo cerrado (lo que Simmel llama «la teleología de los animales»), pensando sobre dicho fondo la diferencia ontológica entre animal y ser humano.

\section{EL MUNDO ES EL ESPÍRITU}

Max Scheler ${ }^{22}$, Martin Heidegger ${ }^{23}$, Kurt Goldstein ${ }^{24}$, Helmuth Plessner $^{25}$, Arnold Gehlen ${ }^{26}$ y Ernst Cassirer ${ }^{27}$ se cuentan entre los que -en el contexto alemán - repiensan con y contra Uexküll la cuestión de lo humano. En esta constelación, la tesis del primero estructurará buena parte del debate. ${ }^{28}$ Scheler comienza El puesto del hombre en el cosmos (1928) describiendo los sucesivos estratos del ser psicofísico y, llegado un momento, afirma sin ambigüedades un dualismo entre vida y espíritu, diferenciándose así de las tentativas del vitalismo psico-metafísico. El primer estrato es vitalista: «el grado ínfimo de lo psíquico», nos dice, «es el impulso afectivo sin conciencia, ni sensación, ni representación» (Scheler 2003, p. 32). Éste se muestra en la planta y en el mundo vegetal, manifestándose esencialmente como un movimiento «íntegramente dirigido hacia fuera», extático, sin remisión a un centro ni repliegue sobre sí. Pura exteriorización de energía ciega. El segundo estrato es uexkülliano, en él un genérico concepto de instinto opera como ordenador del comportamiento animal: «Lo que un animal puede representarse y sentir viene en general determinado y dominado a priori por la relación de sus instintos con la estructura del mundo circundante» (ibid., p. 42). A diferencia de los impulsos ciegos, el instinto «se dirige a componentes del mundo circundante que retornan con frecuencia» y que son de carácter específico (no individual) pero, por otro lado, la energía vegetativa sigue manifestando su potencia de exteriorización, pues los instintos específicos «representan una especialización creciente del impulso afectivo y sus cualidades» (ibid., p. 45). Más allá de algún matiz terminológico, el análisis scheleriano de la

22 Sobre la relación Scheler-Uexküll, véase: Becker 2020; Brentari 2015, pp. 177-181.

23 Sobre la relación Heidegger-Uexküll, véase: Michelini 2020; Muñoz Pérez 2015; Buchanan 2008. Respecto de esta relación es importante notar que, al menos desde 1925-1926, Heidegger tiene conocimiento de la obra de Uexküll (Michelini 2020, p. 125; Buchanan 2008, p. 92).

24 Sobre la relación Goldstein-Uexküll, véase: Ostachuk 2020.

25 Sobre la relación Plessner-Uexküll, véase: Krüger 2020; Brentari 2015, pp.181-185.

26 Sobre la relación Gehlen-Uexküll, véase: Brentari 2015, pp. 185-188.

27 Sobre la relación Cassirer-Uexküll, véase: Brentari 2020; Koutroufinis 2016; Stjernfelt 2011.

28 Sobre la centralidad de Scheler en el debate de la antropología filosófica alemana y, en particular, su recepción en Heidegger y Cassirer, véase: Gordon 2012, pp. 69-77. 
conducta animal está calcado sobre la conceptualización de Uexküll. ${ }^{29}$ Tras describir otros dos estratos (la memoria asociativa y la inteligencia práctica de los «animales superiores»), Scheler finalmente da un salto y pone un ser espiritual, la persona humana, cuyo principio «es ajeno a todo lo que podemos llamar vida» y, más aún, «se opone a toda vida en general» (ibid., p. 60). Tres elementos sobresalen en este nuevo estadio. Primero: la conducta humana se relaciona con objetos «y es motivada, en principio, prescindiendo del estadio fisiológico del organismo humano, prescindiendo de sus impulsos y de las partes externas sensibles del medio» (ibid., p. 63). Segundo: es capaz de «reprimir libremente -o sea, partiendo del centro de la persona- un impulso, o en dar rienda suelta a un impulso reprimido en un principio» (ibid., pp. 6364). Este elemento parece calcado sobre la entelequia del neovitalista Hans Driesch (que puede suspender las actividades fisicoquímicas o relajar dicha suspensión), y será uno de los puntos de ataque de Cassirer. ${ }^{30}$ Tercero: es capaz de modificar «la objetividad de una cosa, modificación que el hombre vive como valiosa en sí y definitiva». De ello, Scheler (ibid., p. 64) concluye:

Este "hallarse abierto al mundo" tiene, pues, la siguiente forma:

Hombre $\leftrightarrow$ Mundo $\rightarrow \longrightarrow \ldots$

Esta conducta, una vez que existe, es por naturaleza susceptible de una expansión ilimitada: hasta donde alcanza el "mundo" de las cosas existentes. El hombre es, según esto, la X cuya conducta puede consistir en "abrirse al mundo" en medida ilimitada. Para el animal, en cambio, no hay “objetos". El animal vive extático en su mundo ambiente, que lleva estructurado consigo mismo adonde vaya, como el caracol su casa.

Así, pues, lo distintivo de lo humano es salir del mundo circundante y abrirse camino al mundo, escapar del Umwelt biológico rumbo al Welt espiritual, sublimar los impulsos y ponerlos a trabajar en una esfera postvital, ganar acceso a un afuera y ser capaz de distancia y objetivación. El par abierto/ cerrado en lo que refiere al mundo, y la idea según la cual solo el ser humano puede relacionarse con objetos y no con meras señales, van a trazar un surco en la discusión. En su curso de 1929-1930 en Friburgo, y sobre la base de

$29 C f$. Scheler 2003, pp. 62-63.

30 Scheler plantea el espíritu no cuenta con fuerza o energía propia sino que la extrae del impulso afectivo, al cual dirige y conduce, subsumiéndolo a un centro (la persona) y conforme una práctica ascética. Cassirer (1975, pp. 158 ss.) subrayará que no queda para nada claro cómo un «espíritu impotente» podría sobreponerse y guiar las «fuerzas ciegas» de la vida. Esta subsunción, agrega, sería posible apelando a las causas finales aristotélicas, al monismo idealista o a la dialéctica hegeliana pero, desprovistos de ellos, nos vemos relanzados al dualismo cartesiano. La crítica es idéntica a la que se dirigía a Driesch: la entelequia debe movilizar algún tipo de energía o carácter material para poder, efectivamente, intervenir en los procesos fisicoquímicos. 
una relectura de Uexküll, Heidegger va a retomar ambos tópicos y también desde un horizonte postvitalista. ${ }^{31}$ Frente al animal que es «pobre de mundo», y que «está encerrado en su medio como en un tubo que ni se extiende ni encoge» (Heidegger 2007, p. 249), presenta al existente humano, al Dasein, como «configurador de mundo», como «abierto al mundo». Paralelamente, subraya que la deficiencia de los animales en su acceso al mundo pasa por el hecho de que no se relacionan con en el ente «en cuanto tal», no perciben algo como algo, sino que son despertados y/o desinhibidos por meras señales. El animal, así, «queda excluido de la manifestabilidad de lo ente» (ibid., p. 299), es incapaz de separar su ser de su mundo. El lagarto que se desplaza por la roca no tiene un acceso al sol como sol, padece la luminosidad bajo la modalidad de la sumersión. Del mismo modo, la garrapata se relaciona con una señal odorífica no el mamífero, la mariposa nocturna con una señal auditiva no con el murciélago, etc. No obstante, Heidegger reconoce con Uexküll que - a diferencia de las piedras- los animales tienen cierto acceso al ente, y toda su meditación se mueve en el estrecho desfiladero que traza la idea según la cual tienen y no tienen mundo. ${ }^{32}$ En este movedizo terreno, ofrece una imagen estremecedora y fascinante. Para él, el animal habita esencialmente en un estado de perturbación y aturdimiento, un estado de conmoción lleno de acechanzas e inminencias, pero, correlativamente, vive cautivado y encantado, alucinado y absorbido por su mundo circundante. Heidegger ilustra la pobreza de mundo del animal evocando un experimento. Se le extirpa a una abeja el abdomen mientras está libado la sustancia contenida en la flor. ¿Qué sucede? La abeja no para de libar, todo lo que ingiere se le escurre a través del abdomen cortado $\mathrm{y}$, al no tener noticia fisiológica del «estar saciada», queda suspendida en el libar. De aquí deriva que la abeja no tiene acceso al ente flor, «está absorta en la comida», está como poseída por un embrujo y no puede «posicionarse frente a la comida» (Heidegger 2007, p. 295). Del conjunto de la reflexión heideggeriana se desprende que el animal «no existe sino que simplemente vive» (ibid., p. 261).

¿Qué dice Uexküll al respecto? En Andanzas por los mundos circundantes de los animales y los hombres (1934), sugiere algunas respuestas. Tras describir el precario mundo de las garrapatas, compuesto sólo de tres círculos funcionales, plantea: «La pobreza del mundo circundante, sin embargo,

31 En Ser y tiempo (1927) Heidegger plantea que la vida no puede de ningún modo pensarse como lo ontológicamente fundamental: la vida no es el ser, sino un «modo de ser» entre otros y, por tanto, es algo del orden de lo óntico-biológico y no de lo existenciario-ontológico. Heidegger (2003, p. 272) denuncia una confusión entre ambos órdenes en Simmel, pero la crítica puede hacerse extensiva a Bergson y a Dilthey, a los cuales, además, les reprocha recaer en formas de psicologismo incapaces de captar las estructuras más profundas de la existencia.

$32 C f$. Heidegger 2007, p. 250. 
garantiza certeza en el obrar, y la certeza es más importante que la riqueza» (Uexküll 2016, pp. 46-47). Esta es solo en apariencia una reivindicación romántica de la vida sencilla pues, para él, mientras que los animales simples poseen un mundo circundante simple, los animales complejos poseen uno más ricamente estructurado. La cuestión no es la cantidad de significaciones que pueda albergar un mundo, sino que este sea idóneo, esto es, que acredite una sinergia entre percepción y acción, entre significación y técnica, entre ser y sentido. Y esto, podría decir Uexküll contra Heidegger, no quiere decir caer en lo impersonal, disolverse en lo inauténtico o ser rehén del mundo del trabajo y la técnica, sino, por el contrario, conjurar esa rara enfermedad que afecta al animal humano y que, de modo insólito, se ha elevado al podio de las experiencias metafísicas: en la angustia no se esconde un «no ser» habilitante de posibilidades sino, simplemente, una vacilación confusa que encuentra su raíz en el desarraigo de las significaciones y en el desencantamiento del mundo.

Asimismo, Uexküll rechaza de antemano la cuestión de si los animales viven aturdidos, encantados o perturbados; para él, estas especulaciones son netamente psicológicas y escapan completamente a nuestro conocimiento. ${ }^{33}$ Por más profunda que sea la meditación comparativa y por más inventiva que sea la psicología animal, nunca podremos transportarnos al mundo interior de otro animal, porque el otro «es siempre una mera formación de nuestra propia apercepción» (Uexküll 1926, pp. 226-227). De lo que sí podemos estar seguros, dice con vena idealista, es de que todo sujeto animal es, vive y existe en un mundo circundante propio. Y esto es válido para todos. No hay una diferencia de naturaleza, sino de grado, entre la cerrazón de los mundos circundantes animales y la de los mundos humanos. La burbuja es, simplemente, un poco más grande. Los distintos ámbitos laborales o profesionales, las distintas especialidades científicas, los mismos mundos artísticos son burbujas entre burbujas, entrañan señales y significaciones que les son inherentes y que constituyen un recorte parcial y minúsculo dentro del vasto campo de lo percibible y experienciable. Uexküll (2016, pp. 155 157), de hecho, pone como ejemplos el mundo circundante del astrónomo, el del químico, y el del físico nuclear. En todos esos mundos hay sujetos que perciben en base a códigos y es el carácter especializado de sus esquemas apriorísticos el que les permite ver lo que para otros congéneres es inexistente.

Respecto de la incapacidad de los seres vivientes para captar los objetos como objetos, Uexküll (1942, p. 19) suscribe plenamente: «jamás un animal entra en relación con un 'objeto'. Merced únicamente a la relación, el objeto se transforma en portador de una significación que el sujeto le imprime».

33 Cf. Uexküll 1951, pp. 72-73.

Contrastes vol. XXVI-Nº1(2021) 
No hay una relación con la naturaleza intrínseca del objeto, pues ésta es o bien «cosa en sí» o bien una «x» que asume diferentes sentidos en función de distintos «tonos» de sujeto. ${ }^{34} \mathrm{~A}$ este carácter incognoscible del objeto en sí Uexküll (1924, p. 302) le pone un nombre, lo llama "contraestructura» (Gegenfüge). La duda que queda flotando es si los animales humanos pueden, efectivamente, relacionarse con un objeto en cuanto tal o, por el contrario, se vinculan siempre con ciertos sentidos del objeto. Uexküll se inclina por la segunda opción.

Ante expresiones como trascender el mundo circundante, abrirse al mundo o habitar lo abierto, Uexküll asume una posición escéptica. Para él, el tránsito desde el mundo cerrado al universo infinito, lejos de haber sido un acontecimiento liberador, ha desencadenado un notable empobrecimiento de los mundos humanos. Una «epidemia» cuantitativa y fisicalista, un «proceso físico de descomposición», se ha apoderado progresivamente del pensamiento humano y, con ello, «la alegría en la búsqueda de nuevas indicaciones [portadores de significación] ha disminuido drásticamente. ¿De qué sirve buscar si sabemos de antemano que todo es sólo una danza de átomos?» (Uexküll 1926, p. 335). En este sentido, frente a las imágenes fisicalistas y/o economicistas del mundo, Uexküll reivindica la estructuralidad y la significatividad que comportan los mundos circundantes, y, más aún, plantea que el concepto físico y el concepto biológico de mundo «están destinados a combatirse como enemigos mortales» (Uexküll 1944: 156).

Esta oposición deja traslucir una impugnación al proyecto moderno en tanto «matematización de la naturaleza», línea que tendrá su desarrollo en La crisis de las ciencias europeas y la fenomenología trascendental (1936) de Husserl. En efecto, así como Uexküll protesta ante la nihilización del mundo circundante a manos de la física, Husserl cuestiona el reduccionismo de la «ciencia natural» fisicomatemática y reivindica un mundo de la vida intersubjetivo como dimensión trascendental humana. Y este mundo, el Lebenswelt, ${ }^{35}$ es una suerte de Umwelt hecho a la medida de los seres humanos: «El concepto de mundo circundante es un concepto que tiene su validez exclusivamente en la esfera espiritual. (...) Nuestro mundo circundante es una configuración espiritual en nosotros y en nuestra vida histórica» (Husserl 2000, pp. 326-327). A diferencia del Umwelt uexkülliano, para Husserl, el Lebenswelt no tiene un origen biológico sino intersubjetivo

34 Cf. Uexküll 1942, p. 19; 2016, pp. 101-108.

35 «El mundo de la vida es el mundo espacio-temporal de las cosas tal y como las experimentamos en nuestra vida pre- y extracientífica y tal y como las sabemos como experimentables, más allá de que de hecho sean experimentadas. Tenemos un horizonte mundano como horizonte de posible experiencia de cosas» (Husserl 2000, p. 146). 
e histórico-cultural, pero su carácter trascendental condiciona todo el campo de la experiencia y actividad humana. Una analogía similar se plantea entre el Umwelt biológico y la mundaneidad heideggeriana, esto es, una «estructura original y constantemente íntegra», un «a priori» ontológico que atraviesa a todos los existentes humanos (Heidegger 2003, p. 53) y que se distingue claramente del espacio físico. Para Sloterdijk (2005, p. 945), de hecho, el ser-en-el-mundo heideggeriano «constituye una respuesta filosófica a la conmoción que le produjo [dicho] concepto biológico». También aquí, la diferencia más evidente es que para Uexküll la estructura a priori de cada especie animal es algo supra-temporal, mientras que para Heidegger el plexo de referencias, la significatividad y otras características del ser-en-el-mundo extraen su sentido de la temporalidad.

En La estructura del organismo (1934), Kurt Goldstein, en lugar de apelar al par cerrado/abierto, recurre a la tensión estático/dinámico para repensar a Uexküll. Por un lado, retoma el punto de partida abierto por la teoría de los mundos circundantes, pero rechaza el carácter fijo y a priori que implicaría la idea uexkülliana. ${ }^{36}$ En este sentido, afirma que, por principio, el Umwelt puede emerger del mundo (Welt) si y sólo si ya hay un comportamiento ordenado, es decir, si el viviente es capaz de realizar sus desempeños (performances), y actualizar lo más posible sus posibilidades, manteniendo su equilibrio interno. Como señala Ostachuk (2020, p. 162), para Goldstein, los organismos no están simplemente ajustados conforme a plan a su mundo circundante, sino que son objeto de múltiples y desafiantes estímulos que pueden destruirlos y malograr su autonomía subjetiva. Por otro lado, rechaza el dualismo del esquema de Scheler y, cuestionando la mera idea de un ascetismo ante a la vida, afirma como principio teórico-metodológico la convicción según la cual «no hay nada 'negativo' en la naturaleza» (Goldstein 1995, p. 146), lo cual lo conduce a pensar al sujeto dentro de una unidad organísmica total donde «la estructuración es siempre estructuración en función de lo que es y no en función de lo que no es» (Simondon 2015, p. 115). De este modo, Goldstein hace de la vida un fenómeno esencialmente holístico: la vida no es sino la tendencia a actualizar lo más posible la esencia del individuo en las condiciones que le son dadas y componiendo su mundo circundante con dichas condiciones; el comportamiento ordenado es aquel que logra, sorteando la angustia y otras patologías, constituir un mundo circundante lo más afín posible a la actualización de la potencia humana. Si bien desde un horizonte

36 «El mundo circundante de un organismo no es de ninguna manera algo definido y estático sino que está continuamente en formación conforme el desarrollo del organismo y su actividad. Se podría decir que el mundo circundante emerge del mundo a través del ser o actualización del organismo.» (Goldstein 1995, p. 85). 
alejado del debate antropológico-filosófico, la visión holista y organísmica de raigambre uexkülliana también se efectuará en la teoría de los sistemas que Ludwig von Bertalanffy desarrolla desde la década del treinta, donde los organismos son vistos como seres dinámicos y activos, y la vida como sistema abierto. ${ }^{37}$

Frente a la crítica que se desprende de las polaridades estático/dinámico y a priorila posteriori, Uexküll concede que puede tener asidero si se piensa en el comportamiento de animales simples pero, en el caso de los complejos (como los pájaros y los mamíferos), no da en el blanco. Porque, si bien cada animal específico comporta una estructura a priori que prefigura un conjunto de percepciones y acciones posibles, es el funcionamiento de esa misma estructura la que lo vuelve capaz de acciones plásticas, acciones basadas en la experiencia y acciones controladas. ${ }^{38}$ Ello implica que el sistema sujetomundo circundante es mucho más fluido de que lo se supone pues, frente al esquema lineal del arco reflejo, moviliza una causalidad circular y retroactiva que articula en el devenir vívido el mundo de acción con el mundo perceptible, acreditando así un particular dinamismo en lo que al individuo viviente refiere.

El par abierto/cerrado que emerge entre Uexküll y Scheler cumple un rol clave en la antropología filosófica de Arnold Gehlen, quien desde 1940 plantea que a diferencia de los animales (que, uexküllianamente, están equipados con órganos específicos y esquemas de percepción innatos), el ser humano llega a la tierra desvalido y desprovisto de órganos e instintos especializados. En este sentido, Gehlen (1993, p. 68) plantea:

Biológicamente considerada, la "apertura al mundo" del hombre (Scheler) es en realidad un factor negativo. La sabiduría de la naturaleza le encubre al animal lo que no debe percibir, por no ser importante para su vida en calidad de enemigo, presa, reclamo sexual, etc. (...) El hombre, en cambio, está expuesto a un exceso de estímulos, a una abundancia de objetos de percepción, comprensibles biológicamente solamente si los asocia a su necesidad de procurarle opciones a la actividad de la cual vive físicamente, y esto en condiciones fortuitas, nunca adecuadas y, por ende, múltiples y variadas en cualquier grado.

Esta fragilidad e indeterminación biológica del ser humano es también su mayor fortaleza, y explica la invención de las técnicas (entre las cuales se cuenta el lenguaje) como prótesis prometeicas que permiten estructurar de modo variable la relación con el medio ambiente. Uexküll no estaría de acuerdo con esto pues, según su estructuralismo vitalista, lo que superficialmente parece producto de variaciones accidentales supone, en

37 Cf. Cassirer 1998, pp. 259-262; Bertalanffy 1960, pp. 18 ss., 1976, pp. 144-160.

38 Sobre estos tres tipos de acciones, véase: Uexküll 1926, pp. 276-278. 
realidad, una interdependencia con un plan estructural más vasto. Asimismo, para él, es imposible que el azar y la indeterminación sean fuentes creadoras de estructuras complejas. Las técnicas, por ejemplo, no son exteriores a la vida sino una parte fundamental e inmanente a ella. La conformidad a plan, de hecho, se expresa en «leyes técnicas» de articulación y ajuste ${ }^{39}$; reglas que, si bien pueden ser descubiertas en la experiencia y progresivamente, remiten a condiciones que las hacen posibles y «sirven de base a la especie, a la familia y al Estado» (Uexküll 2014, p. 147). ¿Cómo distinguir entre las leyes técnicas fundadas que estructuran sinérgicamente las relaciones, y las infundadas que las malogran? Evitando «el dolor», este «castiga toda intrusión en contra del plan de la naturaleza» y muestra que «precisamente el humano, que cree llevar el cetro de la libertad, no puede subsistir sin el azote de la naturaleza» (ibid., p. 147).

En su Antropología filosófica (1944), Cassirer (2009: 46-47) se pregunta «¿Es posible emplear el esquema propuesto por Uexküll para una descripción y caracterización del mundo humano?», y responde:

Es obvio que este mundo no constituye una excepción de esas leyes biológicas que gobiernan la vida de todos los demás organismos. Sin embargo, en el mundo humano encontramos una característica nueva que parece constituir la marca distintiva de la vida del hombre. (...) Entre el sistema receptor y el efector, que se encuentra en todas las especies animales, hallamos en él como eslabón intermedio algo que podemos señalar como sistema "simbólico". Esta nueva adquisición transforma toda la realidad humana. Comparado con los demás animales el hombre no sólo vive en una realidad más amplia sino, por decirlo así, en una nueva dimensión de la realidad. (...) El lenguaje, el mito, el arte y la religión constituyen partes de este universo, forman los diversos hilos que tejen la red simbólica, la urdimbre complicada de la experiencia humana. Todo progreso en pensamiento y experiencia afina y refuerza esta red.

La lectura de Cassirer es más uexkülliana de lo que puede parecer a primera vista. Ya desde 1928, Cassirer rechaza la posibilidad de equiparar a una mera diferencia de grado los mundos de humanos y animales, comparte la idea según la cual los animales no pueden relacionarse con objetos y afirma que, a diferencia de aquellos, los seres humanos son «capaces de forma» (der Form fähig). ${ }^{40}$ Asimismo, en 1944, complementa esta idea con una distinción

39 Si bien no nos es posible desarrollarlo aquí, dejamos constancia de que Uexküll establece una clara distinción entre «mecánica de la naturaleza» y «técnica de la naturaleza» (mientras que la primera se basa en la causalidad eficiente, la segunda remite a relaciones y articulaciones de tipo estructural).

40 Cf. Stjernfelt 2011. 
suplementaria: «Señales y símbolos corresponden a dos universos diferentes del discurso: una señal es parte del mundo físico del ser; un símbolo es parte del mundo humano del sentido. Las señales son 'operadores'; lo símbolos son 'designadores'.» (Cassirer 2009, p. 57). ${ }^{41}$ Sin embargo, su filosofía de las formas simbólicas no está lejos del estructuralismo vitalista uexkülliano. Además de compartir con este un rechazo del vitalismo psico-metafísico y del dualismo metafísico de Scheler, lo anima una convicción similar: los sujetos no pueden no estar en el mundo y habitan necesariamente dentro de estructuras formales, sean éstas de origen biológico o histórico-cultural. La capacidad formadora de los seres humanos, asimismo, no pivotea en la nada, la indeterminación o la conciencia de la finitud, sino en un conjunto de formas simbólicas subyacentes (y sobre las cuales es posible la innovación, el progreso, etc.). En este sentido, Cassirer propone una «fenomenología de la cultura» que permita comprender al ser humano a través del análisis de sus obras $\mathrm{y}$, correlativamente, que habilite una «visión estructural» del sistema de símbolos con los cuales éste se encuentra funcionalmente asociado. ${ }^{42}$ Uexküll moviliza un método análogo: se trata de observar las efectuaciones y actividades de los seres vivientes en el espacio y, por otro lado, de pensar las condiciones estructurales que las hacen posibles. ${ }^{43}$

\section{CONCLUSIÓN}

Del recorrido efectuado se desprende que, en oposición a la teoría de los mundos circundantes, el problema de la diferencia antropológica da lugar a distintas polaridades (cerrado/abierto, estático/dinámico, señal/símbolo, etc.), afirma la imposibilidad del animal para captar objetos neutros y rechaza que pueda hablarse de una diferencia de grado entre los distintos mundos. En efecto, el igualitarismo ontológico que defiende Uexküll en lo que respecta a los mundos circundantes, como hemos visto, es cuestionado y problematizado desde distintos ángulos por sus coetáneos, y serán las lecturas que emergerán varias décadas después de su muerte las que, neutralizando el idealismo de su teoría, reivindicarán dicha horizontalidad anti-antropomórfica. No obstante, más allá de las diferencias, creemos que la oposición tematizada no constituye una contradicción o una oposición extrínseca, sino una oposición correlativa que arraiga en un sistema de pensamiento común y pivotea sobre una serie de premisas compartidas. Entre estas se destacan el desplazamiento crítico con respecto al vitalismo psico-metafísico y al positivismo fisicalista, la promoción de conceptos de totalidad y estructura frente a esquemas analítico-

41 Sobre esta cuestión, véase: Koutroufinis 2016.

42 Cf. Cassirer 2009, p. 108.

43 Cf. Uexküll 1951: 24-25, 55-56. 
atomistas e historicistas-evolucionistas, la voluntad de pensar la subjetividad en correlación al mundo como campo de la significatividad, y la asociación de la cuestión de lo trascendental con la temática del mundo.

En relación con esto último, hemos visto que desde la filosofía se subraya que, a diferencia de los mundos circundantes animales, los mundos humanos no se componen de esquemas a priori de origen biológico, sino de estructuras que se constituyen de modo temporal, intersubjetivo e histórico-cultural. Y ello supone apertura, cierta distancia con los objetos y conocimiento conceptual. Uexküll no está en contra de esto, no niega que en los seres humanos el $a$ posteriori se convierta en a priori y cree que, efectivamente, los humanos median con conceptos el vínculo entre percepción y acción. ${ }^{44}$ Más aún, para él, los mundos circundantes humanos suponen un sistema conceptual que prescribe un orden de visibilidades y experiencias posibles. ¿Qué estructura y articula dicho sistema? La época. ¿Y qué es una época? Uexküll (1942: $150)$ responde: es «un grupo de mundos circundantes humanos homogéneos dentro de un período de tiempo». Con lo cual, perciban de manera mediata o inmediata, los humanos tanto como los animales habitan en mundos circundantes. Y, quizás, hasta las propias epistemes de Foucault no sean sino mundos circundantes epocales.

\section{REFERENCIAS BIBLIOGRÁFICAS}

BECKER, R., «Creative life and the ressentiment of Homo faber: how Max Scheler integrates Uexküll's theory of environment», en F. Michelini y K. Köchy (eds.), Jakob von Uexküll and Philosophy. Oxford-New York: Routledge, 2020, pp. 7388.

BERTALANFFY, L. 1960: Problems of Life. New York: Harper Torchbook.

BERTALANFFY, L. 1976: Teoría general de los sistemas, tr. J. Almela. Madrid: Fondo de Cultura Económica.

BLUMENBERG, H. 2013: Teoría del mundo de la vida, tr. G. Mársico y U. Schoor. Buenos Aires: Fondo de Cultura Económica.

BRENTARI, C. 2015: Jakob von Uexküll - The discovery of the Umwelt between Biosemiotics and Theoretical Biology. Dordrecht: Springer.

BRENTARI, C., «Ernst Cassirer's Reading of Jakob von Uexküll: between natural teleology and anthropology», en F. Michelini y K. Köchy (eds.), Jakob von Uexküll and Philosophy. Oxford-New York: Routledge, 2020, pp. 106-121.

BUCHANAN, B. 2008: Onto-Ethologies. The Animal Environments of Uexküll, Heidegger, Merleau-Ponty and Deleuze. Albany: State University of New York Press.

CASSIRER, E., «"Espíritu” y "Vida” en la Filosofía Contemporánea», tr. R. 
Sierra Mejía, Revista de la Universidad Nacional (tercera época), 14 (1975), pp. 153-173. $\quad$ http://www.revistas.unal.edu.co/index.php/revistaun/article/ view/12407/13008

CASSIRER, E. 1998: El problema del conocimiento IV, tr. W. Roces. México: Fondo de Cultura Económica.

CASSIRER, E. 2009: Antropología filosófica, tr. E. Ímaz. México: Fondo de Cultura Económica.

DILTHEY, W. 1974: Teoría de las concepciones del mundo, tr. J. Marías. Madrid: Revista de Occidente.

FOUCAULT, M. 2002: Las palabras y las cosas, tr. E. Frost. Buenos Aires: Siglo XXI.

FOUCAULT, M. 2011: La arqueología del saber, tr. A. Garzón del Camino. Buenos Aires: Siglo XXI.

GEHLEN, A. 1993: Antropología filosófica, tr. C. Cienfuegos. Barcelona-Buenos Aires: Paidós.

GOLDSTEIN, K. 1995: The organism: a holistic approach to biology derived from pathological data in man. New York: Zone Books.

GORDON, P. 2012: Continental divide: Heidegger, Cassirer, Davos. Cambridge: Harvard Unviversity Press.

HEIDEGGER, M. 2003: El ser y el tiempo, tr. J. Gaos. Buenos Aires: Fondo de Cultura Económica.

HEIDEGGER, M. 2007: Conceptos fundamentales de la metafísica. Mundo, finitud, soledad (1929-1930), tr. A. Ciria. Madrid: Alianza.

HEREDIA, J. M., «Jacob von Uexküll, an intellectual history», en F. Michelini y K. Köchy (eds.), Jakob von Uexküll and Philosophy. Oxford-New York: Routledge, 2020, pp. 17-35.

HEREDIA, J. M., «El problema formas/vida y el estructuralismo vitalista de Jakob von Uexküll», Tópicos. Revista de Filosofía de Santa Fe, 41 (2021). En prensa.

HUSSERL, E. 2000: La crisis de las ciencias europeas y la fenomenología trascendental, tr. J. Muñoz y S. Mas. Barcelona: Altaya.

HUXLEY, J. 1948: Evolution: The Modern Synthesis. London: George Allen and Unwin.

KOUTROUFINIS, S., «Animal and human "Umwelt" (meaningful environment). Continuities and discontinuities», Balkan Journal of Philosophy, 8, 1 (2016), pp. 49-54. http://koutroufinis.net/wp-content/uploads/2016/04/Animal and Human_Umwelt Meaningful_Envir-3.pdf

KRÜGER, H.-P., «Closed environment and open world: on the significance of Uexküll's biology for Helmuth Plessner's natural philosophy», en F. Michelini y K. Köchy (eds.), Jakob von Uexküll and Philosophy. Oxford-New York: Routledge, 2020, pp. 89-105.

KULL, K., «Uexküll and the post-modern evolutionism», Sign Systems Studies, 32 1/2 (2004), pp. 99-114.

MICHELINI, F., «The philosoher's boredom and the lizard's sun: Martin Heidegger's interpretation of Jacob von Uexküll's Umwelt theory», en F. Michelini y K. Köchy (eds.), Jakob von Uexküll and Philosophy. Oxford-New York: Routledge, 
2020, pp. 122-140.

MUÑOZ PÉREZ, E., «El Aporte de Jakob von Uexküll a Los conceptos fundamentales de la metafísica. Mundo, finitud, soledad (1929-1930) de Martin Heidegger», Diánoia, LX, 75 (2015), pp. 85-103. http://dianoia.filosoficas.unam.mx/index. $\mathrm{php} /$ dianoia/article/view/58/1573

OSTACHUK, A., «The organism and its Umwelt: a counterpoint between the theories of Uexküll, Goldstein and Canguilhem», en F. Michelini y K. Köchy (eds.), Jakob von Uexküll and Philosophy. Oxford-New York: Routledge, 2020, pp. 158-171.

PALTI, E., «El "retorno del sujeto". Subjetividad, historia y contingencia en el pensamiento moderno», Prismas. Revista de historia intelectual, 7 (2003), pp. $27-50$.

PALTI, E. 2017: An Archaeology of the Political. Regimes of Power from the Seventeenth Century to the Present. Columbia: Columbia University Press.

SCHELER, M. 2003: El puesto del hombre en el cosmos, tr. J. Gaos. Buenos Aires: Losada.

SIMMEL, E. 2004: Intuición de la vida, tr. J. Rovira Armengol. La Plata: Terramar (Caronte Filosofía).

SIMONDON, G. 2015: Sur la psychologie. Paris: Presses Univesrsitaires de France.

SLOTERDIJK, P., «Atmospheric politics», en B. Latour y P. Weibel (eds.), Making things public: Atmospheres of Democracy. Karlsruhe-Cambridge: MIT PressZKM, 2005, pp. 944-955.

STJERNFELT, F., «Simple animals and complex biology: Von Uexküll's two-fold influence on Cassirer's philosophy», Synthese, 179 (2011), pp. 169-186. https:// doi.org/10.1007/s11229-009-9634-5

UEXKÜLL, J., «La biología de la ostra jacobea», Revista de Occidente, tomo III, 9 (1924), pp. 297-331.

UEXKÜLL, J. 1926: Theoretical Biology, tr. D. L. MacKinnon. New York: Harcourt, Brace \& Co.

UEXKÜLL, J. 1951: Ideas para una concepción biológica del mundo, tr. R. M. Tenreiro. Buenos Aires: Espasa-Calpe.

UEXKÜLL, J. 1942: Meditaciones biológicas. La teoría de la significación, tr. J. M. Sacristán. Madrid: Revista de Occidente.

UEXKÜLL, J. 1944: Teoría de la vida, s/tr. Madrid: Editorial Summa.

UEXKÜLL, J. 2014: Cartas biológicas a una dama, tr. T. Bartoletti y L. C. Adduci. Buenos Aires: Cactus.

UEXKÜLL, J. 2016: Andanzas por los mundo circundantes de los animales y los hombres, tr. M. Guntin. Buenos Aires: Cactus.

WITTGENSTEIN, L. 1997: Tractatus Lógico-Philosophicus, J. Muñoz e I. Reguera. Barcelona: Altaya.

WITTGENSTEIN, L., «Diario filosófico (1914-1916)», tr. J. Muñoz, en Wittgenstein III. Diarios, conferencias. Madrid: Editorial Gredos, 2009, pp. 15-116. 
Juan Manuel Heredia es Profesor Adjunto en la Universidad Pedagógica Nacional y Jefe de Trabajos Prácticos en las asignaturas Ética y Problemas Especiales de Ética del Departamento de Filosofía de la Universidad de Buenos Aires. En el marco de una beca posdoctoral del CONICET, desarrolla su labor de investigación en el Centro de Historia Intelectual de la Universidad Nacional de Quilmes.

Líneas de Investigación:

Historia intelectual; filosofía del siglo XX; Gilbert Simondon, Jakob von Uexküll

Publicaciones recientes:

(2020): «Jakob von Uexküll, an intellectual history», en F. Michelini y K. Köchy (eds.), Jakob von Uexküll and Philosophy. Oxford, New York: Routledge, pp. 17-35.

(2020): «Elementos para pensar el problema de la tecnocracia en Gillbert Simondon», Isegoría. Revista de Filosofía Moral y Política 63, pp. 507-524.

Correo electrónico: herediajuanmanuel@gmail.com 
